tumour would disappear as nsual, he sought no help until the next morning (the day of admission), when he went to a medical man, who told him he had a rupture, and endeavoured for ten minutes to return it. Failing in this, the medi.al man advised him to apply at the hospital.

On admission, a tense elongated tumour, somewhat larger than a goose's egg, was felt in the left inguinal region, extending some way into the scrotum. It appeared very elastic, and coughing gave a dubious impulse. When manipulated, the tumour gave him pain, and as the integuments were already much reddened, no real attempt was made to reduce it. The abdomen was somewhat distended, but not tender. There was no anxious expression, no vomiting, no great spontaneous pain, and the pulse was good. The patient was put to bed and a large enema given, of which only part could be retained. It brought away a small quantity of freces. At 2 P.M. Dr. Roberts Law saw him, and ordered an injection of morphia over the tumour. At 4 P.M., as no alteration was observable in the tumour, the patient was taken into the operating-room and put under ether. After a very short preliminary attempt at taxis, an incision about two inches and a half long was made over the centre of the tumour, and the layers divided down to the sac. On passing the finger towards the abdomen to find the stricture, a small sharp-pointed body was felt protruding through the sac wall outside the external ring. This was seized by the forceps, withdrawn, and proved (microscopically) to be the end of a thin slip of bone, two inches long, by three-sixteenths of an inch broad at its widest part; to the other end of this was attached a fibrous shred, with the colour and odour of fæces. A director having been introduced into the opening in the sac, the sac wall was carefully opened on it; this was found very thick and friable; its internal surface was dark-red. The cavity was filled by a portion of intestine, attached to which were large masses of fat. In this intestine was found a corresponding hole to that in the sac wall, through which the bone was withdrawn. The edges of these holes were of a greyish colour and sloughy appearance. On passing a director through the hole in the upper surface of the gut, the point reappeared at the opposite surface under the fat, where a second opening was found, presenting the same characteristics; thus the bone evidently transfixed the intestine and skewered it in the sac. No obstruction was made out, but one band tighter than the rest was notched, and the finger was passed freely into the abdomen, but the intestine was found adhering to the sac. The contents of the sac were left in position, a drainage-tube was put into the lower angle of the wound, and the upper part was closed by sutures. The operation was performed antiseptically. After the operation the patient was allowed iced milk-and-water, and one grain of opium was given every six hours.

He passed a quiet night, and was not sick. No flatus passed by bowel. Next morning the pulse was 120 , full ; temperature $100^{\circ} 4^{\circ}$. The wound was dressed; the deep parts were healed; the drainage-tube was taken out. In the afternoon he vomited twice, and once in the evening, the vomit being curdled milk in thin colourless fluid. No flatus passed by bowel. On the 17 th the stitches were taken out of wound, which was nearly healed. The parts around looked brawny and dark. During the 17 th retching became more frequent, not much was brought up; the vomit was once only a little greenish. Eructations of wind very troublesome. No flatus passed per anum. The tongue remained moist. The patient took beef-tea, milk, and champagne freely. In the evening the pulse became weaker, and the abdomen slightly more distended. He passed a very restless night, dozing at intervals. In the morning the condition was much worse, the abdomen much more distended. Tongue still moist. Temperature $994^{\circ}$; pulse 124, much weaker. Urine, which had been drawn off by a catheter since operation, was now dark-brown, slightly albuminous, and contained altered blood-corpuscles. Nothing had passed by bowel. The finger was forced into the wound some distance, but let out no pus. The integuments round the wound were darker and more swollen. Ordered four ounces of brandy, and turpentine stupes to be applied to the abdomen. In the afternoon the pulse failed, and the limbs grew cold. Vomiting ceased almost entirely, the breathing became labonred, and death occurred at 11.45 P.M. on the $18 \mathrm{th}$, seventy-nine hours after operation.

The necropsy (sixteen hours after death) was performed by the house-surgeon. On opening up the wound about a drachm of brownish stinking pus escaped from the sac. The interior of the sac was very dirty-lonking. The piece of fat in the sac had become adberent to the walls. There was no constriction in the neck, the finger could be passed into the abdomen. On opening the abdomen the intestines were found much distended. They presented points of injection all over, and had become greasy, having lost their polish. There was no fluid in the abdomen. On turning up the coils from the inner opening of inguinal canal, the colon close to the sigmoid flexure was seen passing over the aperture, and on pulling it it was found to be partially engaged in it. When the neck of the sac was slit up, it was observed that part only of the circumference of the colon was drawn in to the neck, and attached to it was the piece of fatty tissuein the sac. By the fact of one side of the bowel being implicated in the neck, the calibre of the gut was greatly diminished at that point; below this the intestine was flaccid and empty. On cutting ont the piece of gut and opening it longitudinally, an appearance exactly like a diverticulum was presented, which, turned inside out, showed the entrance and exit holes of the bone. The mucous membrane round the one in the upper wall was livid, in the other one the edge was thin in consequence of the perforation in the mucons membrane being smaller than that in the outer coats. There was no mark of constriction, and, except just in the neighbourhood of the holes, the mucous membrane appeared healthy. The kidneys when opened showed somewhat diminished thickness of cortex, which was tougher than natural. The capsule stripped off readily enough, but left a slightly granular surface.

Remarks. - One may observe that in this case the usual symptoms of tight strangulation of the gut were absent, but taking into consideration the advanced age of the patient, it was thought best to operate without unnecessary delay. The operation proved satisfactorily the impossibility of reduction.

The non-passage of flatus or other contents of the in. testine after the operation may have been caused by the non-return of that portion included in the sac, but the lowered vitality incident to the patient's time of life more probably prevented the intestine resuming its normal functions.

The question arises, Would the formation of an arti. ficial anus have by any possibility influenced the ultimate result?

\section{BIRKENHEAD BOROUGH HOSPITAL.}

\section{POISONING WITH PHOSPHORUS.}

(Under the care of Dr. STEverson.)

For the following notes we are indebted to Mr. F. Grenfell Baker, M.R.C.S., senior house-surgeon :-

B. W-, a young woman, aged twenty-two, was carried to the hospital at 6.45 P.M. on Nov, 27th, by a police constable who had found her about three-quarters of an hour previously running about the streets, with, as he said, "flames coming from her mouth and hands."

The patient was a robust, well-made, young woman, and when admitted was in a very excited state, and talking in. coherently. Thick luminous fumes were issuing from the mouth with her breath, and on her hands were patches of a greenish blue-looking substance, which was also luminous in the dark. The woman refused to answer any questions relative to her condition, and did not complain of any pain. A powerful odour of phosphorus was apparent around her. A strong emetic of sulphate of zinc was at once administered in water, and emesis immediately afterwards occurred. The vomited matters consisted of large lumps of undigested meat and potatoes, which when placed in a dark room wereluminous, and smelt strongly of phosphorus. In a few minutes: second emetic similar to the first was given, together with a large quantity of water, which was swallowed without difficulty, and in about three minutes returned, but without any phosphorescent odour or appearance. After this the patient expressed herself as being "all right," and, refusing to remain in hospital, was conveyed to the police court. where she was charged with attempting to commit suicide. She had not long been in the Bridewell, however, when ber condition became so alarming that the authorities sent her back to the hospital, where she was admitted at nine $0^{\circ} \mathrm{clock}$ the same night.

On admission she was perfectly conscions, though some- 
what collapsed and very pale, and was constantly retching and bringing up small quantities of yellow mucus. She was immediately put to bed, with hot bottles to her feet. She complained of great thirst, with pain in the mouth and throat, but she would only occasionally speak, and then in a scarcely audible tone. The pupils were normal, pulse full and regular, and the breathing hurried and shallow. She was very drowsy, but was kept constantly awake. Small quantities of fluid, containing equal parts of milk and limewater, were given at frequent intervals. The patient was getting very cold, and sweating profusely. There was no swelling or tenderness of the abdomen. At 12.30 A.M. no change had occurred. While the patient was being put to bed a half ounce pot, almost empty, of phosphorous paste for killing rats was found concealed about her dress. At 2 A.M. she was breathing freely, respiration thirty in the minute; temperature $100^{\circ}$, pulse 90 , full and regular. Great pain in throat and mouth was complained of, and patient appeared to be in a stupid, half-conscious condition. The eyes were closed, and on being told to open them only twitching movements of the lids occurred. The pupils were normally dilated and responsive to light. Nothing could be got from the patient as to what she had taken, and the few words she uttered were too feebly spoken to be understood. The abdomen was very tense and tympanitic, but did not appear to be painful. An enema of castor oil with tincture of opium was given, which shortly afterwards brought away some normally-looking frees; at the same time the urine was voided, but could not be examined on account of its being mixed with the enema. No phosphorous odour was observed about the evacuation. At this time the breath was still strongly of phosphorus, and the patient restless and sleepy. Milk at frequent intervals was given, together with a solution of morphia every four hours, and a large hot poultice to the abdomen.

Next morning at ten o'clock no change had occurred in her general condition. There seemed to be great tenderness over the throat and epigastrium. The patient appeared to be quite unable either to open her eyes or mouth, or in any way to move, as if from extreme weakness of the necessary muscles; temperature $101^{\circ}$; pulse 104 , and irregular; respiration 26, and irregular. The pupils were normal, but there existed intense photophobia of both eyes. There was profuse perspiration. On examining the chest all the signs of commencing acute inflammation of the larger bronchi and the trachea were evident, and there was great difficulty in swallowing. Mill, together with the whites of eggs, were ordered to be given during the day, and ice to suck. Fifteen drops of tincture of opium in cinnamon water were given three times a day. At 11 A.M., temperature $101^{\circ}$; pulse 106 ; respiration 34. At 2 P.M., temperature $99^{\circ}$; pulse 96 ; respiration 30 . At 4 P.M., temperature 38 ; pulse 68 ; respiration 24 . At 6 P.M., temperature $974^{\circ}$; pulse 70 , irregular and scarcely perceptible ; respiration 24 .

At 10 P.Mr., the nurse in charge sent to say the woman had died suddenly, and on seeing the body a few minutes later the house-surgeon found it lying on its back quite motionless, with no perceptible pulse, respiration, or heart's beat. The body was quite cold, temperature in the vagina $97^{\circ}$, eyes fixed, and she appeared in all respects to have expired. Artificial respiration wasimmediately resorted to, and in a few minutes the woman began to breathe very faintly, and at the end of half an hour's continuous efforts the pulse and heart's beat could just be detected, and respiration fairly carried on, though were irregular. The patient appeared to be quite unconscious. Several relapses occurred at frequent intervals, and artificial respiration had to be kept up till 1 A.M., when the breathing and pulse had much improved, though the temperature only stood at $97 \cdot 4$. The patient was coughing a good deal at this time, and loud râles could be heard all over the chest. No phosphorous odour was noticed in the breath.

Nov, 29th. - The patient had passed a very restless night, coughing continuously, but without any expectoration. She appeared very weak, and the mental condition was unchanged. The abdomen was distended and tympanitic, and the throat and the epigastrium were very sore. There was great photophobia. Temperature $98.8^{\circ}$; pulse 100 , small and irregular; respiration 24, shallow and irregular. Moist xâles were audible over the chest; heart's beat could not be felt, and on the slightest movement the patient appeared to be on the verge of suffocation. She coughed a good deal, but without any expectoration. At midday temperature 99.4 ; pulse 100 ; respiration 24 . At 4 P.M., temperature $98 \cdot 2^{\circ}$; pulse 80 ; respiration 35 . At 6 P.M., temperature $96 \cdot 8^{\circ}$; pulse 80 ; respiration 30 . At 8 P.M., temperature $98 \cdot 2^{\circ}$; pulse 78 ; respiration 30 . No urine or fæecs had been passed during the day, and in the evening the water was drawn off and found to be normal, withont any phosphorescent appearance. The woman had taken iced milk and eggs at frequent intervals, and although there was constant retching, no vomiting occurred. The medicine was repeated during the day.

She passed a quiet night, and on the following morning answered questions put to her in a rational manner, but still in a very low, feeble tone. She complained of pain in the throat and slight epigastric tenderness. The tongue was clean, and the throat did not appear inflamed. She passed two pints of urine during the morning, which was quite normal. Milk was taken freely, and apparently without pain. She was still unable to fully open her eyes, or protrude the tongue. At 11 A.M., temperature $97^{\circ}$; pulse 100 irregular and very small ; respiration 30. At 3 P.M., temperature $98^{\circ}$; pulse 100 ; respiration 24 . At 7 P.M., temperature $98.4^{\circ}$; pulse 128 ; respiration 34 . At 10 P.M., temperature $101^{\circ}$; pulse 90 ; respiration 32 . At 12 temperature $98.4^{\circ}$; pulse 80 ; respiration 30 . The same treatment was adopted as before.

On Dec. lst the patient appeared to be altogether in a totally different condition. She spoke intelligeutly, and said she did not remember anything that had occurred during her illness, but admitted she took the poison. There was no abnominal pain or tenderness, though the abdomen was still somewhat distended and tympanitic. There was very little tenderness about the throat, and slight difficulty in swallowing. The medicine was discontinued, and the patient still kept on a diet of milk and egg, with some bread and butter. The urine and foces were voided during the day, and appeared perfectly normal. Temperature $99^{\circ}$, pulse 100 ; respiration 25 , at 10 A.M. At 10 P.M. the temperature was $98.8^{\circ}$; pulse 90 ; respiration 25 . The eyes were fully opened, and tongue protruded at will.

Next day, but for general weakness, the patient appeared to have fully recovered - no pain or tenderness was any where experienced, and the abdomen was of the natural size. The temperature, pulse, and respiration were normal, and no sickness was complained of. The police authorities removed the patient to the Bridewell, from whence she was taken to the workhouse, where she 'emained for ten days, and was then allowed to return to her friends, being perfectly well.

During the whole time the woman was under observation no signs of jaundice were perceived.

\section{attlevical Sorietties.}

\section{PATHOLOGICAL SOCIETY OF LONDON.}

Parasites in Muscle in Typhoid Fever.-Spontaneous Dis. appearance of Morphlece. - Lichen Ruber.-Cyst in Brain. - Aneurism by Anastomosis. - Suppuration in Larynx.Mitral, Tricuspid, and Aortic Stenosis. - Tumour of Spermatic Cord. -Congenital MTalformation of Rectum.

THE ordinary meeting of the Pathological Society was held on Tuesday, the 20th inst., J. Hutchinson, Esq., President, in the chair. An interesting communication from Mr. W. H. Power of the Local Government Board on the discovery of nematoid worms in the roluntary muscles in typhoid fever was read by Dr. G. Buchanan. Mr. Eve introduced the subject of laryngeal abscess in typhoid fever, and, on the request of the President, Drs. Greenfield and Taylor promised to bring other specimens illustrating it, and raise the discussion again.

Dr. G. Buchanax read a paper on Some Appearances, probably of Parasites, in the Voluntary Muscles of Enteric Fever. The observations which it described were made by his colleague, Mr. W. H. Power, who was led to investigate the subject by finding that an epidemic on board the training-ship Comwall, supposed to be typhoid fever, was really trichinosis. He thereupon commenced the examination of the voluntary muscles in typhoid fever. The first 